\title{
As diferentes perspectivas da qualidade sobre nível de serviço na logística e os desafios do e-commerce
}

The different perspectives of quality on service level in logistics and the challenges of ecommerce

\section{Gabriela Andrade Lacerda de Melo ${ }^{1}$ (b) https://orcid.org/0000-0003-4753-9532}

\author{
Antônio Fernando ${ }^{1}$ \\ ${ }^{1}$ Escola Politécnica de Pernambuco, Universidade de Pernambuco, Recife, Brasil, \\ E-mail do autor principal: Gabriela Andrade Melo.gabrielaandrade@gmail.com
}

\section{Resumo}

Diante de um cenário de valorização do setor logístico e de transporte na cadeia de suprimento, surge a necessidade de entender como os clientes visualizam o serviço logístico e quais fatores compõem o que eles qualificam como um serviço que atende as suas expectativas. Este trabalho apresenta uma análise das diferentes perspectivas dos clientes sobre o nível de serviço e como os indicadores logísticos de satisfação do cliente podem ter diversas abordagens. Adicionalmente, é apresentado como o mundo virtual do e-commerce também contribui para uma mudança na forma de avaliar a satisfação com o serviço realizado e as novas métricas que a internet trouxe consigo ao acelerar e facilitar a interface com o cliente.

Palavras-Chave: e-commerce; logística; transporte; QCAMS;

\begin{abstract}
Facing a scenario of valuation of the logistics and transportation sector in the supply chain, there is a need to understand how customers visualize the logistics service and what factors make up what they qualify as a service that meets their expectations. This paper presents an analysis of the different perspectives of the clients on the service level and how the logistic indicators of customer satisfaction can have several approaches. Additionally, it is presented how the virtual world of ecommerce also contributes to a change in the way to evaluate satisfaction with the service performed and the new metrics that the internet brought with it by accelerating and facilitating the interface with the client.
\end{abstract}

Key-words: e-commerce; logistics; transport; QCAMS. 


\section{Introdução}

Com a globalização crescente e os produtos e serviços tendo que chegar em locais cada vez mais remotos em tempos cada vez mais curtos, a atividade de transportes vem ganhando mais notoriedade e importância dentro da economia nas últimas décadas. Segundo Vivaldini [1] em muitos setores industriais as atividades de transportes representam o maior percentual em termos de custos logísticos, superando até os custos de manter os estoques. Sendo assim, a gestão dos transportes vem sendo vista não como um mal necessário, que era a visão de alguns anos atrás, mas sim como uma vantagem competitiva para as empresas se diferenciarem frente a seus concorrentes.

Com o transporte ganhando cada vez mais importância para o cliente, é de interesse das empresas controlarem de forma mais eficaz se seus serviços estão atendendo satisfatoriamente seus clientes. Entretanto, Simchi-levi [2] ressalta que nos mercados atuais, controlados pelos clientes, não são os produtos ou serviços propriamente ditos que importam, mas o valor percebido pelo cliente. A maneira com que uma empresa mensura a qualidade de seus produtos e serviços evoluiu, da verificação interna da qualidade para a satisfação do cliente. É nesse contexto, de mudança da percepção da qualidade pelos clientes, que o ainda jovem ecommerce, se comparado a logística tradicional, vem enfrentando alguns desafios. Por mais que os serviços de vendas online estejam sendo ampliados e se tornando cada vez mais acessíveis ao consumidor as dificuldades das empresas em cumprir o prazo estão cada vez maiores e mais evidentes [3]. E não apenas o fator prazo, que é o mais perceptível no setor de transporte, mas Hijjar [4] relembra que a cada passo do processo de compra online, voluntaria ou involuntariamente os consumidores avaliam o desempenho das lojas que utilizam. Esse desempenho percebido pode ser fator decisivo para sobrevivência de uma loja virtual, pois poderá influenciar a decisão do consumidor de realizar novas compras ou não mais voltar a consumir naquela loja.

\section{Indicadores QCAMS}

Segundo Albrecht [5], proporcionar a qualidade total em serviços é uma situação na qual uma organização fornece qualidade e serviços superiores a seus clientes, proprietários e funcionários. Por sua vez, conforme Carpinetti [6] a satisfação dos acionistas decorre da satisfação do cliente que se relacionam com a eficácia do negócio. A eficácia do negócio depende de fatores que supram as necessidades dos clientes. Porém, identificar quais as necessidades dos clientes não é uma tarefa simples:

"O produto final de um serviço é sempre um sentimento. Os clientes ficam satisfeitos ou não conforme suas expectativas. Portanto, a qualidade do serviço é variável de acordo com o tipo de pessoa. É importante observar que os serviços possuem dois componentes que devem ser considerados: o serviço propriamente dito e a forma como é percebido pelo cliente" [7]

Segundo Campos [8], existem 5 fatores que são essenciais para avaliar se a satisfação das necessidades dos clientes está sendo atingida, conhecidos como indicadores QCAMS:

- Qualidade Intrínseca: Mede a satisfação do cliente com relação às características de qualidade dos produtos e serviços;

- Custo: Mede o custo-benefício do produto/serviço. Não adianta ter o preço mais barato se o produto/serviço não trouxer um benefício equivalente ao preço.

- Atendimento: A entrega do produto/serviço deve ser feita na quantidade, na data e no local certo;

- Moral: Mede o nível de satisfação das pessoas que trabalham na empresa, sendo possível avaliar se os funcionários trabalham em um ambiente que seja possível exercer um trabalho de qualidade.

- Segurança: Está relacionado a responsabilidade civil do produto, ou seja, a segurança que ele oferecerá a seus usuários.

Traduzindo para linguagem de logística e transportes, os principais indicadores seriam segundo Uehara [9]: Disponibilidade de produto, tempo de ciclo de pedido, consistência do prazo de entrega, frequência da entrega, flexibilidade do sistema de 
entrega, sistema de recuperação de falhas, sistemas de informação de apoio, apoio na entrega, física, apoio pós-entrega. Porém existem muitos outros fatores, além desses. A junção desses fatores forma o indicador mais comum na logística chamado de nível de serviço.

\section{Nível de Serviço}

Como afirmam muitas teorias sobre serviço ao cliente, para atingir a satisfação do cliente é necessário que ele perceba que o serviço prestado tenha um desempenho melhor ou igual ao que ele esperava receber.

"A comparação entre essa percepção de desempenho e a expectativa do consumidor em relação a cada item de serviço fornecerá o gap de satisfação. Quanto maior esse gap, mais insatisfeito estará o consumidor com o serviço prestado" [4]

Porém, antes de avaliar os gaps, existe um grande desafio que seria identificar quais fatores são levados em consideração na avaliação pelo cliente do nível de qualidade de um serviço prestado. Segundo Simchilevi [2] na logística o indicador mais comumente utilizado para quantificar a adaptação de uma empresa ao mercado é o nível de serviço. Normalmente o termo está relacionado a capacidade de entregar o produto na data combinada com o cliente. Porém, para outros autores esse conceito é mais amplo.

Para Ballou [10] o nível de serviço logístico é a qualidade com que o fluxo de bens e serviços é gerenciado. É o resultado final de todos os esforços logísticos da firma. Segundo o autor é bastante comum encontrar diferentes formas de medir o nível de serviço, mas o fator-chave sempre é achar o conjunto de valores logísticos que as empresas oferecem aos seus clientes para garantir sua fidelidade.

Segundo Fleury \& Hijjar [11] o conceito de serviço ao cliente é a qualidade de um conjunto de dimensões que incluem a facilidade de completar a transação, disponibilidade de produto, o prazo de entrega a consistência do prazo de entrega, o sistema de informações de apoio, o sistema de remediação de falhas e o desempenho e a flexibilidade da operação de entrega física.

Existem várias pesquisas que buscam priorizar quais elementos são mais importantes para a satisfação do cliente com relação ao serviço logístico. Perreault [12] mostrou a correlação, variando de 0 a 1 , entre nível de serviço e satisfação do cliente, conforme Tabela 1. Os principais fatores foram tempo de entrega, variabilidade do tempo de entrega e informação sobre o andamento do pedido. Em $4^{\circ}$ lugar está o serviço de urgência, fator pouco encontrado em outras pesquisas.

\begin{tabular}{|c|c|}
\hline Elemento do Nível de Serviço & Índice \\
\hline Tempo médio de entrega & 0,76 \\
\hline Variabilidade do tempo de entrega & 0,72 \\
\hline Informações sobre andamento do pedido & 0,67 \\
\hline Serviço de Urgência & 0,59 \\
\hline Método para emissão de ordens & 0,56 \\
\hline Resolução de queixas & 0,56 \\
\hline Exatidão do preenchimento de pedidos & 0,46 \\
\hline Política para devolução & 0,44 \\
\hline Procedimento de cobrança & 0,36 \\
\hline
\end{tabular}

Tabela 1: Elementos que compõem o nível de serviço. Fonte: Perreault [12].

Já Ballou [10] afirma que existem vários outros fatores que influenciam o nível de serviço:

- $\quad$ Elementos pré-transação: São aqueles que são necessários antes da entrega propriamente dita, para garantir que nada ocorra em desacordo com o combinado com o cliente e estabelecem um ambiente para ser prestado um bom nível de serviço. Uma política por escrito estabelecendo a meta de nível de serviço, qual o procedimento da empresa em casos de devolução e faltas, são exemplos de elementos que dão mais segurança para o cliente e que mostram o que a http://dx.doi.org/10.25286/repa.v2i4.903 
empresa está disposta a oferecer. Outros elementos que também aumentam a confiança na relação cliente-te-fornecedor é a criação de planos de contingência em casos de greves ou desastres naturais, que criam uma estrutura que para implementar a política de nível de serviço.

- Elementos de transação são os aspectos que influenciam diretamente na entrega produto ao cliente e no resultado percebido. Níveis de estoque ajustados, seleção do meio de transporte, determinar procedimentos para processamento de pedidos são elementos de transação do nível de serviço. Eles influenciam diretamente em como o cliente avalia o nível do serviço: se o tempo de entrega foi conforme acordado, se a ordem de compra está conforme desejada, se a mercadoria recebida está em bom estado, se havia disponibilidade de estoque.

- Elementos pós-transação: São aqueles fatores de apoio ao consumidor após o momento da compra do produto. Geralmente são serviços oferecidos para ajudar os consumidores em casos de produtos defeituosos, serviços de atendimento para realizar reclamações, solicitações, devoluções, assim como retorno de embalagens, como pallets por exemplo.

Esses elementos são muitas vezes o fator diferencial que fazem com que os clientes sejam fidelizados a marca, pois podem trazer sua satisfação, mesmo após a compra.

\section{Desafios do e-commerce}

Quando se trata de operações de serviços, o varejo é um dos que mais sofrem com a alta complexidade do gerenciamento logístico.

"Operações de varejo em geral requerem soluções sofisticadas de distribuição física, gestão de estoque e níveis de serviço. Um dos desenvolvimentos recentes em termos de prática de varejo foi o desenvolvimento do canal de distribuição baseado na internet" [13]

O mercado virtual chegou como uma alternativa à logística tradicional, trazendo a comodidade da internet que facilita bastante a interface com o cliente, permitindo fácil e rápido acesso na compra da mercadoria. Entretanto, também existem suas desvantagens, como o complexo desafio de fornecer uma cadeia de abastecimento logístico, considerada retaguarda do negócio, que consiga atender as necessidades e expectativas de entrega com a mesma comodidade, praticidade e velocidade que a linha de frente oferece, como citam Fleury \& Monteiro [14]. Os autores ainda relatam que no Natal de 1999 nos EUA foi onde pela primeira vez foi chamado atenção para o assunto, pois houve um boom de vendas pela internet que ocasionou o colapso no sistema de atendimento e entrega. Nesta situação, previu-se que cerca $25 \%$ dos clientes que fizeram suas compras natalinas pela internet não tiveram suas expectativas satisfeitas, pois muitos receberam mercadorias equivocadas ou entregues após o Natal.

Conforme ressalta Uehara [9], é bastante comum encontrar notícias na imprensa com depoimentos de consumidores que tiveram experiências desagradáveis ao realizar compras pela internet. Os principais problemas relatados são atrasos com relação ao prazo de entrega prometido, produtos entregues com avarias, erros de cobrança e cancelamento de pedidos por falta de produto. Essas dificuldades se dão pelo fato do perfil de entrega de e-commerce ser bastante diferente da logística tradicional.

A tabela 2 sumariza as principais diferenças entre a logística tradicional e o e-commerce, em termos de tipo de carregamento, tamanho médio do pedido, destinos e demanda.

\begin{tabular}{|c|c|c|}
\hline Variáveis & $\begin{array}{c}\text { Logística } \\
\text { Tradicional }\end{array}$ & E-commerce \\
\hline Carregamento & Paletizado & $\begin{array}{c}\text { Pequenos } \\
\text { Pacotes }\end{array}$ \\
\hline Tamanho Médio & $>\cup \$ 1000$ & $<\cup \$ 1000$ \\
\hline do pedido & Concentrados & $\begin{array}{c}\text { Altamente } \\
\text { Dispersos }\end{array}$ \\
\hline Demanda & Estável & Incerta \\
\hline
\end{tabular}


Tabela 2: Comparativo logística tradicional $\mathrm{X}$ ecommerce. Fonte: Fleury \& Monteiro [14]

Fazendo um paralelo com indicadores QCAMS, segue uma análise mais detalhada de como os indicadores de e-commerce se diferenciam quanto a Qualidade Intrínseca, Custo e Atendimento (Entrega). Para os indicadores de Moral e Segurança não foi realizada análise comparativa pois entende-se que não há diferença significativa na logística tradicional e e-commerce.

- Qualidade Intrínseca: No e-commerce, onde as entregas são via operações B2C (Businessto-Customer), há um aumento na manipulação de itens não-paletizados nos depósitos, diminuindo a movimentação por lotes e aumentando a movimentação de pequenos pacotes. Os produtos que na logística tradicional normalmente são embaladas em caixas e paletes podem no, ecommerce, ser de uma natureza física diferente e vir a requerer uma forma de transporte específica. Como diz Novaes [15] Mercadorias resfriadas, por exemplo, exigem manuseios adicionais e cuidados especiais na sua embalagem e transporte precisando de maior nível de coordenação das operações nos centros de distribuição. Como cada pacote é manuseado com muito mais frequência que no B2B (Business-to-Business), a probabilidade de avaria aumenta. Quando o produto perde sua capacidade de exercer sua função básica, é o primeiro sinal para o consumidor que a qualidade intrínseca não atendeu às expectativas.

- Custo/frete: Outro desafio para o e-commerce em comparação a logística tradicional é o elevado valor do frete por unidade. Como há perda de escala de volume, o custo fixo do frete que antes se diluía por várias unidades agora se concentra em poucos volumes.

Um exemplo do setor supermercadista, na pesquisa de Hijjar [4], um dos motivos para os clientes não voltarem a comprar no supermercado virtual foram os preços e taxas cobrados, que foram considerados muito elevados. Para os clientes o custo benefício não foi suficiente para quererem utilizar o ecommerce, pois o valor agregado pelo serviço 122 adicional de entrega não foi suficiente para compensar os preços cobrados.

- Atendimento: Por se tratarem de entregas geralmente para pessoa física, o perfil do pedido geralmente é o mesmo: poucos volumes para cada endereço. Por esse motivo, a roteirização das entregas pode se tornar extremamente difícil. Quando existe um pedido para uma cidade remota, muitas vezes precisa-se aguardar até que uma grande quantidade de pedidos se acumulem para aquela região, para ser economicamente benéfico enviar um veículo para lá. Isso pode aumentar o tempo de entrega para os clientes. Além disso, como bem pontua Novaes [15], há uma extrema dificuldade de previsão de demanda nesses casos. Muitas empresas tradicionais ao colocarem parte de seus negócios a serem comercializados pela internet foram surpreendidos com uma avalanche de pedidos, sobrecarregando o planejamento logístico dos setores de expedição [15]. O autor ainda complementa, ressaltando que a previsão de demanda na logística tradicional pode se basear no histórico de vendas e na média de pedidos daquele cliente já conhecido. Entretanto na logística eletrônica a demanda é muito variável com altas e baixas em períodos aleatórios, pois são geralmente novos clientes.

\section{Conclusões}

Com a logística e distribuição ganhando um papel cada vez mais importante nos negócios das empresas, é de interesse das mesmas avaliar como utilizá-la como uma vantagem competitiva nos seus negócios. O primeiro passo para tal, é entender como os clientes visualizam a logística e distribuição dos produtos e quais suas expectativas com relação aos serviços oferecidos. Normalmente é possível classificar os critérios de avaliação de um serviço em 5 aspectos: Qualidade Intrínseca, Custo, Atendimento, Moral e Segurança. Um dos indicadores mais comuns na área de logística e distribuição é o nível de serviço. Sua definição e suas métricas variam entre autores e empresas, podendo simplesmente medir se a entrega foi feita no prazo acordado, até medir se o cliente está satisfeito com os serviços pós-venda. É interessante http: / / dx.doi.org/10.25286/repa.v2i4.903 
que o máximo possível de variáveis estejam envolvidas nessa medição para garantir que o monitoramento de todos os aspectos que o cliente observa esteja ocorrendo. Entretanto, as métricas para medir a satisfação do cliente vem mudando, pois com o e-commerce algumas expectativas foram modificadas. Com o mundo virtual extremamente rápido e acessível durante as compras, os clientes transferem essas mesmas expectativas para os serviços de entrega, o que vem se tornando um grande desafio para as transportadoras. Com o maior manuseio dos produtos aumenta-se o nível de avarias, além da previsão de demanda bastante incerta, que dificulta a roteirização. Essas são algumas das dificuldades que as transportadoras vem enfrentando quando se trata de e-commerce.

\section{Referências}

[1] M. Vivaldini, S.R.I. Pires. Operadores Logísti-cos - Integrando Operações em Cadeias de Su-primento. 1. Ed. São Paulo: Editora Atlas, 2010.

[2] D. Simchi-Levi, P. Kaminsky, E. SimchiLevi. Cadeia de Suprimentos Projetos e Gestão. 3. ed.Porto Alegre: Editora Bookman, 2010.

[3] J.M. Azevedo, C.M.T. Rodriguez, A.G.R. Leza-na, A Logística de Distribuição em vendas Vir-tuais: De gargalo eletrônico para vantagem competitiva. Comitê Científico do RIRL, 2004.

[4] M.F. Hijjar. Oportunidades no setor supermer-cadista vitual: Uma análise sob perspectiva do consumidor. Revista Tecnologística, novembro 2012.

[5] K. Albrecht. Total Quality Service. Seminário Internacional, página 24, 1992.

[6] L.C.R. Carpinetti. Gestão da Qualidade, 2. Ed. São Paulo: Editora Atlas, 2012.

[7] A.L. Las Casas. Qualidade Total em Serviços. 6.ed. São Paulo: Atlas, 2008.

[8] V. F. Campos. Controle da Qualidade Total (no estilo Japonês). Belo Horizonte: Fundação C- hristiano Ottoni, 1992. Revista de Engenharia e Pesquisa Aplicada (2017) vol:pp.x-pp.y

[9] L. Uehara. Evolução do Desempenho logístico no varejo virtual do Brasil, Revista Tecnologís-tica, março 2002.

[10] R.H. Ballou. Logística Empresarial. 1.ed. 1993; 21 reimpressão 2009. São Paulo: Atlas, 2009.

[11] P.F. Fleury, M.F. Hijjar. Serviço ao Cliente e desempenho logístico no varejo virtual do Brasil. 2000.

[12] J.W.D, Perreault, F.A. Russ. Physical distribu-tion service in industrial purchase decisions. Journal of Marketing, n.40, página.8, 1976.

[13] H.L. Correa, M. Caon. Gestão de Serviços.1.ed. 2002; 11 reimpressão 2012. São Paulo: Atlas, 2012.

[14] P.F. Fleury, F.J.R.C, Monteiro. O Desafio Lo-gístico do e-commerce, 2000.

[15] A.G. Novaes. Logística e gerenciamento da cadeia de distribuição: estratégia, operação e avaliação. Rio de Janeiro: Campus, 2001. 